\title{
Impactos da gestão de aulas baseadas em problemas verbais de Matemática sobre a aprendizagem ${ }^{1}$
}

\section{Impacts of lessons management based on Mathematics words problems on learning}

\author{
Maria Alice Veiga Ferreira de Souza ${ }^{2}$
}

\begin{abstract}
RESUMO
Este artigo apresenta potenciais êxitos e constrangimentos apresentados em aulas baseadas em problemas verbais escritos de Matemática impactando sobre a aprendizagem de alunos do oitavo ano do ensino fundamental português. Os problemas foram propostos por futuros professores em meio ao estágio supervisionado na Universidade de Lisboa. Os dados emergiram de estratos da interação/intervenção de um professor-orientador com três estagiárias sobre as gestões de suas aulas baseadas em problemas verbais escritos de Matemática. Foram identificados êxitos tais como associar figuras geométricas às respectivas expressões algébricas e conduzir as explicações por questionamentos diretos sobre o tema e constrangimentos como confusões conceituais matemáticas, comandos escritos sem sentido para os alunos, termos sem a devida contextualização para o contexto matemático. A investigação contou com apoio teórico de autores e pesquisadores sobre a resolução de problemas, a compreensão de textos de enunciados de problemas de Matemática e a formação na/da prática docente.

Palavras-chave: gestão de aulas; problemas verbais; Matemática; prática docente; aprendizagem.
\end{abstract}

\footnotetext{
ABSTRACT

This article presents potential successes and constraints presented in lessons based on written words problems of mathematics impacting on the

DOI: $10.1590 / 0104-4060.46978$

1 Agradecimento: Pesquisa científica financiada pela Fundação de Amparo à Pesquisa e Inovação do Espírito Santo (FAPES).

2 Instituto Federal do Espírito Santo. Programa de Pós-Graduação em Educação em Ciências e Matemática. Vitória, Espírito Santo, Brasil. Rua Barão de Mauá, n 30 , Jucutuquara. CEP: 29040-860.E-mail: alicevfs@hotmail.com
} 
learning process of students in the eighth year of Portuguese classes in an elementary school. Those problems have been proposed by future teachers during a supervised internship at the University of Lisbon. The data emerged from strata of interaction/intervention of a teacher-coach with three interns regarding the actions of their lessons based on written words problems of Mathematics. Successes have been identified such as the association of geometric figures to their algebraic expressions and the conduction of explanations by direct questions on the subject, as well as constraints as confusing mathematical concepts, written commands with no meaning for students, terms without proper contextualization to the mathematical context. The research has been supported by authors and researchers in the field of problem solving, the understanding of statements of math problems and the training in/of teaching practice.

Keywords: lessons management; words problems; Mathematics; teaching practice; learning.

\section{$O$ contexto a discutir}

Propor tarefas matemáticas - atividades, exercícios, resolução de problemas, modelagem etc. -, orais ou escritas, faz parte do dia a dia de professores de Matemática e, portanto, é útil que esse tema seja investigado e discutido quando da formação de professores, uma vez que a maneira como são elaboradas e apresentadas, podem gerar êxitos e constrangimentos na compreensão dos alunos e, consequentemente, em suas resoluções, como afirmam Kotovsky, Hayes e Simon (1985), Correa e Oliveira (2011) e Souza e Guimarães (2015), para o caso de problemas verbais de Matemática.

Alguns desses êxitos e constrangimentos foram mapeados por investigadores da Educação Matemática, muitos deles recorrendo a aspectos linguísticos e psicológicos que explicassem esses reflexos sobre o pensamento dos alunos em meio a tarefas matemáticas. (ABEDI; LORD, 2001; KRUTETSKII, 1976; BUTTS, 1997; SUYDAM, 1997; AIKEN, 1972; SMOLE; DINIZ, 2001; FONSECA; CARDOSO, 2005; PÓLYA, 1945, 1981; ROMANATTO, 2012; SHOENFELD, 1985; VIEIRA, 2001; CORREA; OLIVEIRA, 2011; PONTE; BRANCO, 2013; SOUZA; GUIMARÃES, 2015).

Estimular a tarefa de resolução de problemas em aulas de Matemática é indicado por vários autores e investigadores da Educação Matemática (PÓLYA, 1945, 1981; SHOENFELD, 1996; NCTM, 1989, 2000), não só por ser via de aplicação de conhecimentos, como por meio de aprendizagem e de motivação 
que desperte interesse pelo estudo de conteúdos matemáticos. Pelo lado da motivação do aluno, Butts (1977, p. 32) diz que "o verdadeiro prazer em estudar Matemática é o sentimento de alegria que vem da resolução de um problema", mas, acrescenta que, os docentes devem estar atentos aos fatores que motivam alguém a querer resolvê-lo e cita como primordial a maneira como o problema é formulado.

Pelo lado do ensino de resolução de problemas, há de se promover o desenvolvimento de competências específicas que só a prática docente proporciona. A prática pode ser, portanto, fonte de conhecimento profissional, sendo uma componente da formação inicial de professores. A prática letiva traz ao primeiro plano aspectos ligados ao pensamento, às reflexões, aos desejos e propósitos do futuro professor. Esses aspectos foram estudados por autores como Schön (1991, 1992), Elbaz (1983), Fenstermacher (1994) e Clandinin (1985, 1986), e confrontados, em seu conjunto, por Guimarães (2008). Esses autores afirmam existir um conhecimento que emerge da prática letiva, com exceção de Clandinin que nega haver um conhecimento, mas sim, uma experiência. De todo modo, esses autores são contrários à ideia de uma racionalidade técnica que prega que o conhecimento profissional seja uma aplicação pura e simples do conhecimento científico e técnico ao contexto prático, visão sobre a qual concorda-se.

Diante desse cenário, foram investigados potenciais êxitos e constrangimentos presentes na gestão de aulas baseadas em problemas verbais escritos de Matemática impactando sobre a aprendizagem de alunos e propostos por professores em fase de formação inicial. Para esse fim, foram perseguidos os seguintes objetivos: 1) identificar palavras e/ou estruturas frasais escritas de enunciados de problemas de Matemática que impactem positivamente/negativamente sobre os alunos de professoras-estagiárias; 2) verificar a organização escrita dos problemas de Matemática propostos por professoras-estagiárias que impactem em êxitos ou constrangimentos sobre a compreensão pelos alunos; 3 ) avaliar os significados produzidos pelos alunos a partir da proposta escrita de resolução de problemas pelas professoras em formação; 4) averiguar a necessidade e a consistência de explicações complementares orais aos enunciados escritos de resolução de problemas propostos pelas professoras em formação.

\section{Enquadramento teórico}

Os estudos de Pólya (1945), ao longo dos tempos, mantiveram-se como uma sólida referência para investigadores e professores interessados no tema. 
Para ele, a resolução de um problema de Matemática é um processo composto por quatro etapas: 1 - a compreensão do problema; 2 - a elaboração de um plano para sua resolução; 3 - a execução do plano, e 4 - análise retrospectiva (looking back). Essas etapas atraíram a atenção, tanto de investigadores em Educação Matemática, como em Psicologia Cognitiva que, a partir das premissas de Pólya, acrescentaram importantes ingredientes, trabalhando-os em investigações que culminaram em outras propostas teórico-educacionais mais profundas e detalhadas.

Uma delas, a fase da compreensão do problema, despertou interesse de investigadores sobre os impactos da linguagem nessa etapa da resolução de problemas por alunos. Abedi e Lord (2001), por exemplo, tomaram problemas de Matemática com enunciados verbais do National Assessment of Educational Progress, que avalia o desempenho de alunos americanos nessa disciplina escolar, e os reescreveram com estrutura verbal mais simples, reduzindo essa complexidade, de acordo com indicações de profissionais dessa área, sem alterar a tarefa matemática. Em entrevistas individuais, trinta e seis estudantes do oitavo ano foram solicitados a escolher quatro problemas, apresentados aos pares em sua forma original e modificada. Em seguida, o pesquisador pedia que lessem os problemas em voz alta e identificassem palavras ou trechos que poderiam ser difíceis ou confusos.

Os resultados revelaram que a maior parte dos estudantes preferiu os textos modificados, alegando serem mais familiares, por fazerem mais sentido, por terem ideia clara do que se deve fazer, por serem mais curtos e por não haver palavras complicadas. Por outro lado, os que preferiram os textos originais alegaram serem mais interessantes ou mais desafiadores. Ainda vale mencionar dessa investigação que, ao lerem os problemas em voz alta, os pesquisadores observaram pausas em palavras não familiares ou construções que interrompiam, de algum modo, o fluxo de compreensão, tais como: "certos", "referência", "todo" e "particular", além de relerem trechos substituindo a voz passiva por voz ativa.

Outros avanços científicos seguiram a partir das sugestões de Pólya (1945) para a fase da compreensão do problema. É o caso de Suydam (1997) que, além de aspectos citados por Abedi e Lord (2001), informa que a complexidade frasal e a sequência de apresentação da informação ser diferente da que será usada na resolução tornam a compreensão mais difícil.

Pelo lado do professor quanto à sua atuação com alunos mediante a propositura de problemas de Matemática, concorda-se com Schön $(1991,1992)$ de que haja nesse ínterim: 1 - um conhecimento na ação - conhecimento emerso na prática; 2 - uma reflexão na ação - pensar sobre o que se faz, enquanto se faz e; 3 - uma reflexão sobre a ação - pensar sobre o que se fez. Esse é um dos 
objetivos de um estágio supervisionado: proporcionar experiências que revelem ao futuro professor um repertório de conhecimentos e reflexões iniciais que, possivelmente, levariam muito tempo para ocorrer, se ocorrerem, ao longo de sua trajetória profissional.

O estágio supervisionado faz mais do que compartilhar experiências ou alertar sobre práticas didáticas pertinentes/não pertinentes. Ele pode contribuir para a formação da própria identidade do futuro professor por meio das reflexões e investigações sobre sua própria prática. As aulas, seguidas de reflexões, contribuem para a modelagem de um estilo próprio e, portanto, idiossincrático sobre sua maneira de ensinar.

Conhecer as indicações como as de Pólya (1945) para a condução de alunos como resolvedores é útil, mas não suficiente, há de colocá-las em prática. É como saber tudo o que se deve fazer para andar de bicicleta, mas não ser o bastante para fazê-lo, de fato - andar de bicicleta. É preciso fazer. Esse é um dos papéis do professor-orientador do estágio e formador de professores: o de promover essas experiências, discuti-las e levar o futuro professor ao conhecimento na ação, à reflexão na ação e à reflexão sobre a ação.

A esse propósito, Pólya (1945) afirmou que o professor deve despertar a capacidade de resolução de problemas mediante questionamentos e interferências que devem ser realizados em momentos certos. Krutetskii (1976), Abedi e Lord (2001), Smole e Diniz (2001), Correa e Oliveira (2011) e tantos outros pesquisadores revelaram outras recomendações e cuidados acerca da formulação dos problemas e que podem e devem integrar a prática do estágio supervisionado a serem explicitadas quando das análises dos enunciados nesse trabalho. Essa prática também interessa aqui, especificamente quanto à formulação de problemas de Matemática por professores em formação inicial.

\section{Procedimentos metodológicos}

Esse trabalho identifica, apresenta e discute estratos da interação/intervenção de um professor-orientador com suas estagiárias (aqui denominadas de professoras-estagiárias), especificamente quanto à condução de aulas sobre problemas verbais escritos de Matemática, como principais veículos para alcance dos objetivos tanto do professor-orientador, quanto das professoras-estagiárias: a aprendizagem de Matemática por alunos.

Para essa discussão, foram analisados três estratos de propostas escritas de problemas de Matemática elaborados, cada um, por três professoras-estagiárias 
(nominados de maneira fictícia como Ana, Bia e Clara) que cursavam a disciplina de Prática de Ensino Supervisionada do Instituto de Educação da Universidade de Lisboa, um dos focos de estudo do pós-doutoramento da autora deste artigo nessa mesma Instituição. Essa análise foi realizada à luz dos autores atrás mencionados, sobretudo de Pólya, Abedi e Lord, Suydam, e precedeu e sucedeu a aplicação das tarefas em sala de aula por essas professoras-estagiárias.

Todas as tarefas foram propostas em aulas de uma hora e meia com alunos do oitavo ano do que chamamos no Brasil de Ensino Fundamental. A quantidade de alunos em cada aula girou em torno de vinte e cinco a vinte e oito minutos. Esses estudantes contavam com idade de 15 anos, aproximadamente, e as aulas foram ministradas no turno da manhã de escolas da periferia de Lisboa, no horário das aulas regulares de Matemática. Esses alunos já estavam integrados com as professoras-estagiárias, porque elas já vinham ministrando aulas há, aproximadamente, um mês. As aulas foram assistidas pela autora do artigo, pelo professor-orientador da disciplina de Prática de Ensino Supervisionada (igualmente orientador do pós-doutoramento da autora do artigo) e pelo professor titular de Matemática daquela turma. Nenhum desses ouvintes interveio no trabalho das professoras-estagiárias ao longo das aulas.

Logo a seguir às aulas, a autora, o professor regular de Matemática, o professor-orientador e a professora-estagiária se reuniram reservadamente em uma sala para discutir e analisar os êxitos e constrangimentos apresentados pelos alunos a partir da intervenção da professora-estagiária. A participação da autora nas reuniões continuou sendo como ouvinte e observadora, tal como nas aulas, sem manifestações orais, escritas ou gestuais que pudessem ser traduzidas como intervenções.

Trata-se, portanto, de um trabalho de cunho qualitativo e descritivo, pautado na análise do material escrito e oral das professoras-estagiárias, bem como na condução docente e percepção dos significados apresentados pelos alunos quando da aplicação em aulas de resolução de problemas, além de contar com aspectos pertinentes das reuniões que sucederam as aulas.

Ressalta-se que as tarefas elaboradas pelas professoras-estagiárias foram entregues ao professor-orientador antes de sua aplicação aos alunos, mas nenhuma intervenção deste com aqueles foi realizada previamente às aulas.

Os problemas tinham como temas principais: perímetro e área de retângulos, manipulações de expressões algébricas, sequências e expressões algébricas, monômios e polinômios. As aulas foram conduzidas de maneira dialogada sobre o conteúdo e a resolução dos problemas, esses últimos sendo discutidos e corrigidos na lousa pelas professoras-estagiárias. 


\section{Descrição, discussão e análise dos estratos de aulas de Matemática}

Pela praticidade, apresentar-se-ão estratos das aulas que mereçam destaque no que diz respeito à resolução de problemas nas aulas e nos problemas propostos pelas professoras-estagiárias, bem como sobre a gestão em sala de aula e as discussões do professor-orientador em momentos posteriores sobre os assuntos em tela.

\section{Estrato 1:}

Ana, professora-estagiária, propôs a tarefa da Figura 1 aos alunos, e deu-lhes, aproximadamente, uma hora para resolvê-los. A tarefa foi entregue por escrito em uma folha antes elaborada, reservando-se espaços em branco para sua resolução.

FIGURA 1 - PROBLEMAS SOBRE PERÍMETRO DO RETÂNGULO OFERECIDOS AOS ALUNOS DO OITAVO ANO PELA PROFESSORA-ESTAGIÁRIA ANA (GRIFOS DA AUTORA).

1. Considerem um retângulo.

1.1 - Sabendo que a altura é $32 \mathrm{~cm}$ e a base é $30 \mathrm{~cm}$ determinem o valor do perímetro do retângulo.

1.2 - Determinem o valor da altura sabendo que a base é $20 \mathrm{~cm}$ e o perímetro é $124 \mathrm{~cm}$. E se a

base for $21 \mathrm{~cm}$ qual terá de ser o valor da altura para que o perímetro não se altere?

1.2.1 Se $a$ for a medida da altura e b medida da base, escrevam uma fórmula que relaciona $a \mathrm{e}$ $b$.

1.3 - Sabendo que $P=2 a+2 b$ escrevam uma expressão para:

$1.2 .2 a$

$1.2 .3 b$

FONTE: A autora (2017).

Nesse tempo, Ana visitou os alunos em suas carteiras esclarecendo dúvidas que são objetos de análise aqui. Após esse momento, foi à lousa para corrigir com a turma a tarefa, sempre questionando os alunos e pedindo que um e outro apresentassem seu raciocínio para os demais. Os questionamentos estão em sintonia com o que Pólya acredita ser uma boa prática para a condução na resolução de problemas, por fazer despertar as capacidades matemáticas que ele diz serem inerentes a cada um. Os alunos avançavam, paulatinamente, na resolução. Ela dizia: "o que queremos aqui?", "que operação fizeram?", "alguém desenvolveu de modo diverso? Mostra-nos. O que acham, é semelhante?".

Nesse momento, um aluno perguntou o que seria "semelhante" e Ana afirmou ser o mesmo que "igual". A explicação não foi adequada, pois há dife- 
renças no contexto matemático entre igualdade e semelhança. Possivelmente, esse aluno fará alguma confusão em problemas futuros que usem essa palavra. É preciso que as palavras façam parte do léxico dos alunos em suas diferentes semânticas. Por exemplo, a palavra "semelhante" no contexto de polígonos guarda uma proporção entre seus lados e igualdade entre seus ângulos. Esse poderia ter sido um argumento para explicar a palavra semelhante. No entanto, Ana usou o termo como sinônimo de "parecido", "próximo de". Esse fato mereceu destaque pelo professor-orientador em momento posterior, o que fez com que Ana refletisse sobre sua ação e, em seguida, sugerisse outro modo de abordagem. A dificuldade com palavras da língua materna que possuem significados específicos na Matemática foi uma das dificuldades de compreensão apresentadas por alunos e reveladas nas pesquisas de Abedi e Lord (2001), Suydam (1997), Smole e Diniz (2001), Correa e Oliveira (2011).

Realça-se que alguns tempos verbais da tarefa de Ana estão no plural: “considerem", “determinem", "escrevam". Essa é uma maneira de dizer que eles poderiam realizar a tarefa em conjunto, caso assim desejassem, o que está em sintonia com a disposição das carteiras em duplas e com o objetivo de desenvolvimento de cooperação e tolerância planejados por Ana.

Pelo lado da linguagem e organização escrita da proposta, o item 1.2 da tarefa gerou dúvidas quanto às palavras "perímetro" e "não se altere" que foram sanadas com as explicações de Ana, aluno a aluno, reservadamente em suas carteiras, mas que poderiam ter sido evitadas com a reescrita dos textos das tarefas. Pelo lado da disposição no papel, os itens 1.2.2 e 1.2.3 estão após o item 1.3 porque a professora-estagiária entendeu que eles fossem subitens do 1.2, apesar de o comando vir do 1.3, o que gerou muitas dúvidas para os alunos. A proposta do item 1.3, portanto, pareceu ser outro constrangimento: "escrevam uma expressão para". Mas, o que é escrever uma expressão para? $\mathrm{Na}$ reunião com o professor-orientador, Ana explicou que pretendia que os alunos reescrevessem $P=2 a+2 b$, isolando $a$ (no item 1.2.2) e isolando $b$ (no item 1.2.3). Destaca-se, igualmente, que a resposta do item 1.2.1 estava no texto do item 1.3, o que foi sublinhado por alguns alunos.

A linguagem usada no item 1.3 não foi compreendida pelos alunos tal como Ana pretendeu gerando constrangimentos e muitas dúvidas. O cuidado com a escrita de tarefas é essencial porque integra a primeira etapa da resolução de problemas. A compreensão do texto da tarefa é responsável pela construção de uma representação mental que os prepara para as etapas seguintes. (KRUTETSKII, 1976). E por que Ana as elaborou dessa forma? A professora-estagiária alegou estar em sintonia com a maneira de abordagem dos livros didáticos. Eis o apoio requerido por Ana para elaboração de sua tarefa. Com isso, cresce a responsabilidade de autores de livros didáticos por serem veículos legítimos 
para apoio ao professor, tal como, aliás, confirmado em investigação de Souza (2001). Uma proposta alternativa dada pelo professor-orientador e pelo professor titular para a tarefa de Ana está apresentada na Figura 2:

\section{FIGURA 2 - UMA PROPOSTA DE REESCRITA DOS PROBLEMAS SOBRE PERÍMETRO DO RETÂNGULO}

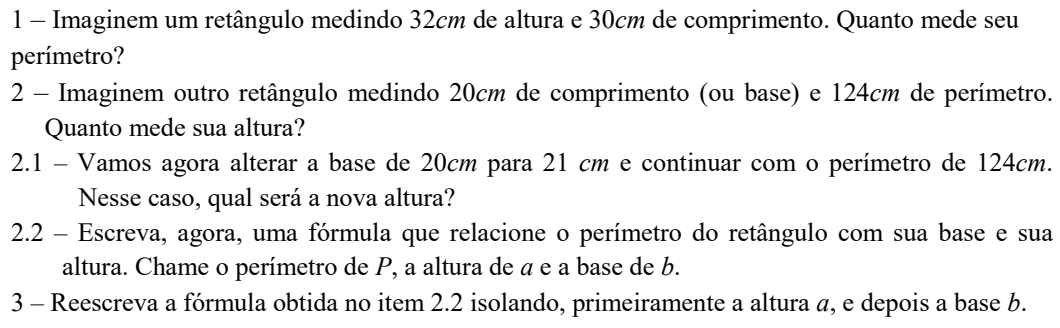

FONTE: A autora (2017).

Não se pode perder de vista que formar alunos em resolução de problemas inclui o trato com aspectos da linguagem. Em aulas ou anos escolares mais avançados, o professor pode usar linguajar mais direto, na medida em que eles se apropriem da linguagem específica da Matemática, ou que saibam estabelecer correspondência entre os termos. Como ilustração, assinala-se que foi escrita a palavra "comprimento" no item 1 . No item 2 foi dado um sinônimo para comprimento (= base) no contexto do problema e da Matemática. A partir do item 2.1, pôde-se usar livremente a palavra "base", pois houve sua inserção ao contexto da Matemática. Mesmo tomando essas providências, o professor não está livre do inusitado pelo próprio caráter de imprevisibilidade de aulas ancoradas em resolução de problemas. Um aluno formulou a seguinte pergunta ao seu colega: "se eu virar o retângulo, a altura não será base também?". Observe que, ainda que a tarefa fosse reescrita como a da Figura 2, a dúvida desse aluno não teria sido sanada. Seria necessária a intervenção oral do professor, o que não é desejável a princípio, pois o aluno deve ser capaz de ler e compreender o enunciado sem contar com quaisquer explicações adicionais. Para isso, é preciso que o enunciado seja bastante claro e que o aluno esteja preparado para lidar com a leitura no contexto matemático.

Ser professor de Matemática é despir-se de um olhar singular sobre os objetos matemáticos a favor da pluralidade de olhares. Ser aluno de Matemática (a professora-estagiária assim o é, até então) é poder estar no conforto de só se preocupar com um cognitivo: o seu. O professor, ao contrário, precisa desenvolver a capacidade de perceber a diversidade de entendimentos e saber lidar com ela. Esse é um grande desafio. 


\section{Estrato 2:}

Segue na Figura 3 a tarefa proposta por Bia aos seus alunos.

\section{FIGURA 3 - PROBLEMAS SOBRE EXPRESSÕES ALGÉBRICAS OFERECIDOS AOS ALUNOS DO OITAVO ANO (GRIFOS NOSSOS)}

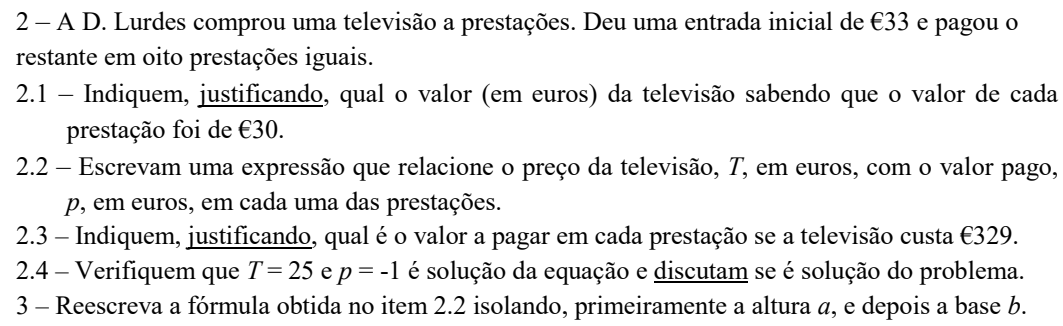

FONTE: A autora (2017).

Tal como Ana, Bia distribuiu as folhas de papel que continham a tarefa proposta e deu-lhes tempo de, aproximadamente, cinquenta minutos para realizarem e, em seguida, visitou os alunos em suas carteiras esclarecendo dúvidas por eles apresentadas. Ao final do tempo, pediu a contribuição da turma para a correção de cada item proposto. Os questionamentos estavam sempre presentes em seu discurso, seguindo as indicações de seu professor-orientador e estando em sintonia com as premissas de Pólya e de outros autores. Alguns deles eram: "Quanto D. Lurdes deu de entrada?", "E ela vai pagar em quantas prestações?"etc. Novamente, os alunos progrediam em suas compreensões, sanando dificuldades de compreensão textual.

Apesar de a intervenção oral ter sido positiva, os textos das tarefas apresentavam pontos como potenciais constrangedores. Os comandos "justificando" e "discutam" (itens 2.1, 2.3 e 2.4) exigem do aluno uma análise crítica sobre a situação-problema. Essa análise não costuma ser trivial para alunos de oitavo ano. É preciso dar-lhes os primeiros passos para o desenvolvimento desse espírito crítico. Não se trata de interpretar o texto em língua portuguesa, mas, para além disso, analisar o contexto do problema em termos matemáticos. Pode-se dizer que, oralmente, Bia esboçou alguma discussão desses itens, mas não os fez formalizá-los por escrito com suas próprias palavras e não promoveu discussões sobre essas produções, perdendo a oportunidade de desenvolver esse viés tão importante para o pensamento matemático: o pensamento crítico.

Outro ponto a discutir é sobre o item 2.4. Os alunos não compreenderam a intenção de Bia ao propô-lo. Em reunião após a aula, ela explicou ter desejado que os alunos percebessem que, apesar de matematicamente correto, ter-se $T=$ 25 e $p=-1$, de fato, para esse problema seria impossível, uma vez que a entrada 
inicial de $€ 33$ seria maior que o preço total da televisão $(T=25)$. A proposta do item poderia ter sido melhor conduzida se a intervenção de Bia tivesse proporcionado a discussão que o comando pedia. Uma opção seria construir uma tabela na lousa com os protocolos dos alunos a partir de seus questionamentos e, daí, gerar debates.

\section{Estrato 3:}

Por fim, a tarefa proposta por Clara está apresentada na Figura 4. Assim como Ana e Bia, Clara estipulou tempo para sua resolução de, aproximadamente, cinquenta minutos, após a distribuição da tarefa em folhas de papel. Por solicitação, os alunos também receberam a visita da professora-estagiária em suas carteiras, o que deixou indícios de constrangimentos sobre suas compreensões textuais.

FIGURA 4 - PROBLEMAS SOBRE EXPRESSÕES ALGÉBRICAS E SEQUÊNCIAS OFERECIDOS AOS ALUNOS DO OITAVO ANO (GRIFO MEU)

1 - Considerem a sequência de figuras.
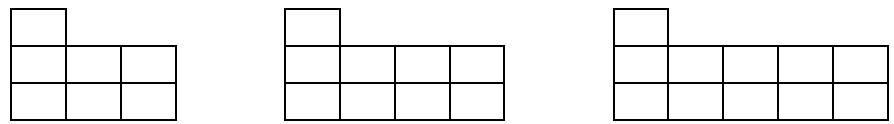

O António, o Baltazar e a Cristina escreveram as seguintes expressões gerais na sequência anterior:
António
Baltazar
$(n+2)+(n+2)+1$
$2(n+1)+3$
Cristina
$2 n+5$

Comentem as expressões encontradas pelos três alunos.

FONTE: A autora (2017).

Essa tarefa mereceu muitas observações do professor-orientador sobre a formulação do problema por Clara. O que significa " $n$ " nas expressões dos três alunos? A explicação veio somente no nível oral ao ser questionada: "n é o número da figura". Mas, onde está a indicação numérica em cada figura?

Além disso, mais uma palavra que não esclarece o que os alunos deveriam fazer: "comentem", gerando, assim, muitos constrangimentos. O que é comentar na Matemática? As palavras devem fazer sentido para os alunos para que haja comunicação de ideias. Se ainda não fazem sentido, o professor deve preencher essa lacuna do mesmo modo como foi feito com a palavra "base" nos problemas da Figura 1. Posteriormente, na reunião com o professor-orientador, Clara não soube explicar o que os alunos deveriam fazer diante do comando "comentem". 
Uma sugestão dada pelos presentes para melhoria desse enunciado foi a indicação de uma pequena estória que contextualizasse a situação para o aluno. A estória tem o poder de auxiliar na construção da representação mental (SOUZA; GUIMARÃES, 2015) que, por sua vez, o ajudará nos próximos passos da resolução. Apresenta-se uma opção de reescrita desse problema na Figura 5, dada pelos presentes na reunião.

\section{FIGURA 5 - UMA PROPOSTA DE REESCRITA DOS PROBLEMAS SOBRE EXPRESSÕES ALGÉBRICAS E SEQUÊNCIAS}

1 - Os alunos António, Baltazar e Cristina observaram uma sequência de figuras igual a que se mostra abaixo.

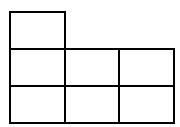

Figura 1

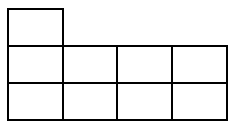

Figura 2

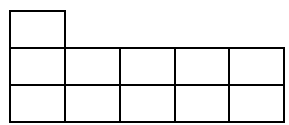

Figura 3

Em seguida, perceberam como a próxima figura dessa sequência era construída e escreveram expressões algébricas que representassem a construção de qualquer uma das figuras. Combinaram que n seria o número da figura. Explique como cada um construiu a sua expressão.
António
Baltazar
$(n+2)+(n+2)+1$
$2(n+1)+3$
Cristina
$2 n+5$

FONTE: A autora (2017).

\section{Outros destaques realizados pelo professor-orientador às professoras- -estagiárias}

Nas reuniões pós-aulas, o professor-orientador teve oportunidade de discutir tópicos relevantes e que emergiram das aulas dadas pelas professoras-estagiárias nos momentos de reflexão conjunta. Muitas dessas orientações poderiam estar inseridas no corpo dos enunciados, ou mesmo em sua gestão oral em resolução de problemas, favorecendo a compreensão dos alunos. Algumas delas foram:

1- A associação de expressões algébricas a figuras geométricas foi positiva;

2- O esclarecimento sobre o que é um monômio foi útil, mas o professor deve também dizer o que não é um monômio e dar exemplos e contraexemplos; depois, pedir que os alunos deem exemplos e contraexemplos; 
3- Os exemplos são bons, mas os contraexemplos também. As dúvidas em torno de soma de monômios poderiam ter sido sanadas com um exemplo $(4 \mathrm{a}+5 \mathrm{a}=9 \mathrm{a}$ é possível $)$ e um contraexemplo $\left(4 \mathrm{a}+5 \mathrm{a}^{2}\right.$, a soma não é possível); para além desses, valeria mostrar exemplos de soma com mais de dois monômios $(2 b+5 b+10 b=17 b ;-3 c+2 c-c$ $=-2 \mathrm{c}$ ), o que não foi feito;

4- Os exemplos e contraexemplos devem ser diversificados. No caso dos monômios, é útil apresentar exemplos com coeficientes com mais de um algarismo, com partes literais com mais de uma letra (2ab; $20 \mathrm{~b}^{2} \mathrm{c}$; -3 mn são monômios), discutir o caso de o "1" não aparecer nem no coeficiente e nem no expoente $\left(1 \mathrm{c}=\mathrm{c}=\mathrm{c}^{1}=1 \mathrm{c}^{1}\right)$, usar expoentes diferentes de " 1 " nas partes literais etc.;

5- Sempre questionar os alunos por escrito ou oralmente; o professor deve devolver aos alunos as perguntas elaboradas por eles; o professor não deve responder aos próprios questionamentos;

6- Preferência por perguntas mais diretas (Que operação fez? Fez algum desenho?); Evitar perguntas amplas e que não contribuem para que o aluno avance, ao contrário, parecem paralisar (O que pensou? Qual foi o raciocínio?);

7- Ter cuidado com a escrita do texto dos problemas; cada palavra deve fazer parte do léxico dos alunos e serem entendidas dentro do contexto da Matemática;

8- Cobrar do aluno o comando do texto, ou seja, pedir o respeito ao que está sendo pedido na tarefa.

Essas indicações sobre a prática letiva, oral ou escrita, estão em sintonia com o que apontam Pólya (1945), Schön (1991; 1992), Elbaz (1983), Fenstermacher (1994) e Clandinin (1986), além da própria experiência do professor-orientador. As professoras-estagiárias pareceram compreender e concordar com as observações do professor-orientador. Seus protocolos forneciam dicas de que elas haviam produzido conhecimento ao reavaliarem suas propostas escritas e intervenções orais e pretenderem aplicar esses conhecimentos nas próximas aulas (conhecimento na ação). Do mesmo modo, parece ter ocorrido reflexão em determinados momentos das aulas (reflexão na ação) ao mencionar a tomada de decisões em função de determinadas reações dos alunos. Houve, nitidamente, reflexão sobre suas ações nas reuniões com o professor-orientador (reflexão sobre a ação) expressas nas discussões e contrapontos ali colocados. Apesar de serem passos iniciais, o estágio proporcionou influências que, provavelmente, farão parte da formação da prática desses futuros profissionais em aulas de resolução de problemas. 


\section{A concluir}

O estágio supervisionado integra uma das três formações iniciais de professores de Matemática: a formação prática, ao lado da formação matemática e da formação para o ensino da Matemática. É nele que, usualmente, se proporciona ao futuro professor desenvolvimento de competências iniciais inerentes às situações da prática e que são desenvolvidas a partir do que Schön chamou de conhecimento na ação, reflexão na ação e reflexão sobre a ação.

$\mathrm{Na}$ formação prática docente também devemos considerar a formação de alunos resolvedores de problemas, por ser este um dos temas fundamentais do ensino da Matemática. Há, nesse sentido, indicações sobre a condução de aulas vindas de autores como Pólya, além de outros que sugerem cuidados com a escrita de textos de problemas: Abedi e Lord, Smole e Diniz, Krutetskii, Souza e Guimarães, por exemplo. Essas e outras sugestões precisam ser praticadas no seio de aulas de Matemática. O modo como as professoras-estagiárias formularam e organizaram enunciados de problemas levaram a êxitos e constrangimentos no processo de aprendizagem apontadas por esses autores.

Esse trabalho investigou a prática de três professoras-estagiárias em ensino supervisionado da Universidade de Lisboa ao ministrar aulas para alunos de oitavo ano em escolas da periferia de Lisboa. Além das aulas, reuniões, em seguida, com o professor-orientador formaram a base de dados para as análises de seus protocolos sobre a prática letiva das futuras docentes.

Muitas sugestões dadas pelo professor-orientador a respeito da formulação das tarefas propostas e de sua gestão foram sendo reavaliadas pelas professoras-estagiárias. De maneira geral, as aulas e reuniões revelaram pontos positivos - a prática do questionamento aos alunos e a associação de expressões algébricas a figuras geométricas, por exemplo -, bem como pontos a serem repensados - a reescrita do texto dos problemas, uso e diversidade dos exemplos e de contraexemplos, etc.

As reuniões com o professor-orientador pareceram ter cumprido com as indicações de Schön sobre a promoção do conhecimento na ação, a reflexão na ação e a reflexão sobre a ação, no quesito enunciados de problemas, o que reforça a utilidade do estágio supervisionado para a formação da prática do futuro professor de Matemática na formulação de enunciados e gestão de aulas baseadas em problemas de Matemática. 


\section{REFERÊNCIAS}

ABEDI, J.; LORD, C. The language factor in Mathematics tests. Applied Measurement in Education, v. 14, n. 3, p. 219-234, 2011.

AIKEN, L. R. Language factors in learning mathematics. Review of Educational Research, v. 42, n. 3, p. 359-385, 1972.

BUTTS, T. Formulando problemas adequadamente. In: KRULIK, S.; REYS, R. E. (Orgs.). A Resolução de Problemas na Matemática Escolar. São Paulo: Atual, 1997. p. 32-48.

CLANDININ, D. J. Personal practical knowledge: a study of teacher's classroom images. Curriculum Inquiry, v. 14, n. 4, p. 361-385, 1985.

CLANDININ, D. J. Classroom pratice, teacher images in action. London: The Falmer Press, 1986.

CORREA, J.; OLIVEIRA, G. A escrita do problema e sua resolução: o entendimento intuitivo acerca da combinatória. Educar em Revista, Curitiba, n. especial 1, p. 77-91, 2011.

ELBAZ, F. Teacher thinking, a study of practical knowledge. London: Croom Helm, 1983.

FENSTERMACHER, G. The knower and the known: the nature of knowledge in research on teaching. Review of Research in Education, v. 20, p. 3-56, 1994.

FONSECA, M. C.; CARDOSO, C. A. Educação Matemática e letramento: textos para ensinar Matemática, Matemática para ler o texto. In: NACARATO, A.; LOPES, C. (Orgs.). Escritas e Leituras na Educação Matemática. Belo Horizonte: Autêntica, 2005. p. 63-76.

GUIMARÃES, H. Perspectivas sobre o conhecimento do professor. Diálogo Educacional, v. 8, n. 25, p. 819-839, 2008.

KOTOVSKY, K; HAYES, J. R.; SIMON, H. A. Why are some problems hard? Evidence from Tower of Hanoi. Cognitive Psychology, v. 17, p. 248-294, 1985.

KRUTETSKII, V. A. The psychology of mathematical abilities in schoolchildren. Chicago: The University of Chicago Press, 1976.

NCTM (National Council of Teachers of Mathematics). Curriculum and evaluation standards for school mathematics. Reston VA: NCTM, 1989.

NCTM (National Council of Teachers of Mathematics). Principles and standards for school mathematics. Reston VA: NCTM, 2000.

PÓLYA, G. How to solve it. Princeton, New Jersey: Princeton University Press, 1945.

PÓLYA, G. Mathematical discovery. New York, NY: Wiley, 1981.

PONTE, J. P. da; BRANCO, N. Pensamento algébrico na formação inicial de professores. Educar em Revista, Curitiba, n. 50, p. 135-155, dez. 2013. 
ROMANATTO, M. C. Resolução de problemas nas aulas de Matemática. Revista Eletrônica de Educação, v. 6, n. 1, p. 299-311, 2012.

SCHOENFELD, A. Porquê toda essa agitação acerca da resolução de problemas? In: ABRANTES, P; LEAL, L. C.; PONTE, J. P. (Eds.). Investigar para aprender matemática. Lisboa: APM e Projecto MPT, 1996. p. 61-72.

SCHOENFELD, A. H. Mathematical problem solving. New York, NY: Academic Press, 1985.

SCHÖN, D. The reflective practitioner: how professionals think in action. London: Avebury, 1991.

SCHÖN, D. Formar professores como profissionais reflexivos. In: NÓVOA, A. (Ed.). Os professores e a sua formação. Lisboa: D.Quixote, 1992. p. 79-91.

SMOLE, K.; DINIZ, M. I. Ler e aprender Matemática. In: SMOLE, K.; DINIZ, M. (Orgs.). Ler, escrever e resolver problemas: habilidades básicas para aprender Matemática. Porto Alegre: Artmed, 2001. p. 69-76.

SOUZA, M. A. V. F. de; GUIMARÃES, H. M. A formulação de problemas verbais de Matemática: porquê e como. Quadrante, v. XXIV, n. 2, p. 135-162, 2015.

SOUZA, M. A. V. F. de. Uma análise de discursos no ensino e aprendizagem de função. Dissertação de Mestrado (Educação) - Universidade Federal do Espírito Santo, Vitória, ES, 2001.

SUYDAM, M. N. Desemaranhando pistas a partir da pesquisa sobre resolução de problemas. In: KRULIK, S.; REYS, R. E. (Orgs.). A Resolução de Problemas na Matemática Escolar. São Paulo: Atual, 1997. p. 49-73.

VIEIRA, E. Representação mental: As dificuldades na atividade cognitiva e metacognitiva na resolução de problemas matemáticos. Psicologia, Reflexão e Crítica, v. 14, n. 2, p. 439-448, 2001.

Texto recebido em 05 de junho de 2016. Texto aprovado em 26 de agosto de 2016. 